\title{
Research of Front Seat Design Parameters on Rear Seat Passenger in Front Crash
}

\author{
Fei Zhao and Jiao Hongyu \\ School of Mechanical Engineering, Changshu Institute of Technology, Jiangsu, China
}

\begin{abstract}
Key word: Front Impact; Rear Seat Passenger; Seat Design Parameters; MADYMO
Abstract: In order to study the influence of front seat parameters on rear seat passenger when front crash happens, this article uses the MADYMO software to establish the rear seat passenger constraint system model which including car bodies, safety belts and a 5\% dummy for impact simulation. The simulation values are close to test ones after contrasted with the vehicle impact test. The influence of design parameters including the front seat headrest and backrest parameters on passenger HIC, T3MS, femur force is researched by this model. With the optimized parameters, the rear passenger head, chest and leg injury are decreased so that the safety of rear passenger can be effectively improved.
\end{abstract}

\section{Introduction}

In China, the rear seat of car is highly used and most of rear passengers are children or elders. But these people's lives are not effectively protected(Munemasa 2005). The main reasons are that rear seat is not rich configured as front seat, rear seat belt usage is low, and the rear belt is easily invalid. Previous studies on the rear passenger safety are mainly about the rear seat belt usage, the rear belt stiffness, belt retractor locking performance, and rear seat cushion angle(Ralf 2004). There is little research on the front seat parameters influence on the rear occupant safety.

In order to study the influence of front seat parameters on the rear seat passenger in front crash, this article uses the MADYMO software to establish the rear seat passenger constraint system model. In vehicle frontal impact, the rear occupant head is easily impacting the front seat headrest, and other parts of the occupant are easily impacting the front seatback(Astrid 2006, Joseph 2006). This article mainly analyzes the influence of front seat headrests and backrest parameters on injury to the rear passenger, and finds the best parameter to protect the rear passenger safety.

\section{System model configuration}

The rear seat passenger constraint system model consists of three main components including car bodies, safety belts and a 5\% dummy.

\subsection{Car Bodies}

Car bodies consist of floor, front seat, back seat and headrests. Floor is modeled by the rigid plane, and seats and headrest are modeled by the finite element model. The seat slide is connected to the vehicle floor by mean of a translational joint, and the slide rail is connected to the reference space by a fixed joint. Cushion and backrest, backrest and headrest are connected by revolute joints.

\subsection{Dummy Model}

Based on C-NCAP 2012, a hybrid III 5\% female dummy is set in the left of rear seat, specify the initial state for Dummy by command INITIAL.JOINT.POS(Jo 2007, Beheshti 2010). Accurately positioning the dummy by dynamic balance method. 


\subsection{Belt Model}

The three point belt model is used in this research. Contacted with the dummy part we use the finite element modeling, and the other parts of the belt model are multi-rigid-body models(Jo 2009). When using finite element belts, one needs a separate pre-simulation to apply the belt.

Figure 1 show the rear seat passenger constraint system model.

\subsection{Contact Specification}

In MADYMO there are three main types of contact:Contact between ellipsoids, cylinders and planes, contact between FE-surfaces and MB-surfaces, contacts between finite elements. This article we use MB_MB (contact between floor and foot) and MB_FE (contact between dummy and belt, contact between dummy and seats).

\subsection{Acceleration field model}

There are two main accelerations: gravity acceleration and $\mathrm{X}$-axis acceleration. $\mathrm{X}$-axis acceleration is shown as figure 2.

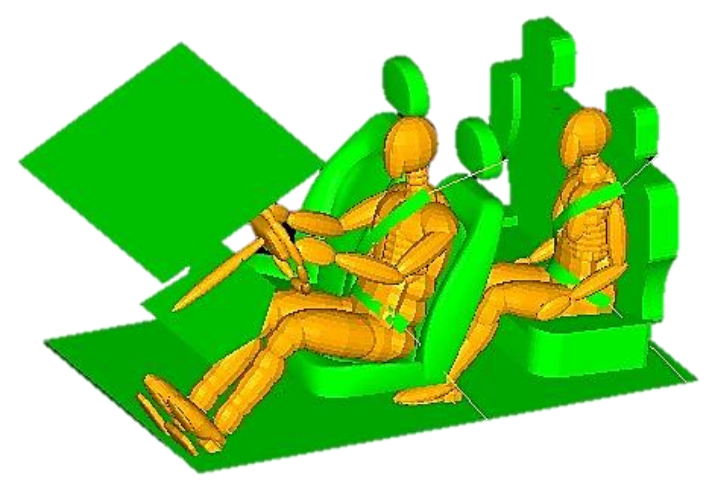

Figure 1 .Rear seat passenger constraint system model

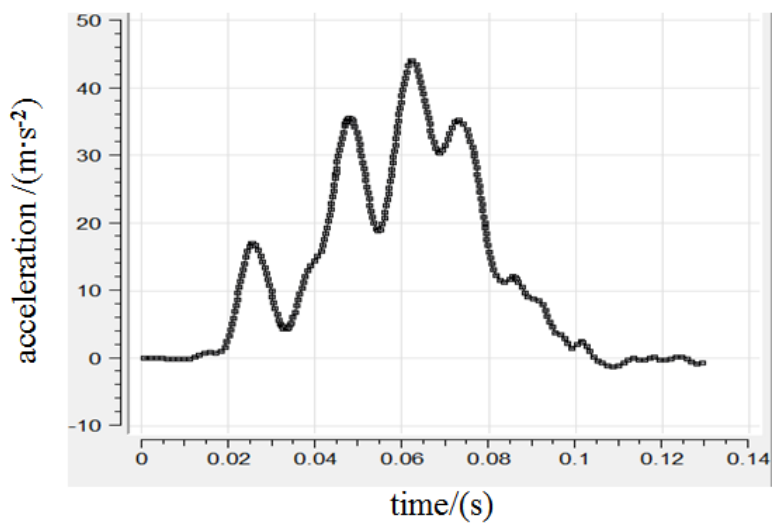

Figure 2. X-axis acceleration

\section{Model confirmation}

The verification of the model follows the "bottom-up" principle. Separately verify this model from the leg, hip, chest, head .Force and acceleration signals meet the basic characteristic about "start 
time, shape, peak, peak time, and pulse width ". Table 1 shows the comparison of experimental results and simulation results.

Table 1: Comparison of experimental results and simulation results

\begin{tabular}{lccc}
\hline Damage index & Test & Simulation & Error \\
\hline Head acceleration $/\left(\mathrm{m}^{-\mathrm{s}^{-2}}\right)$ & 685 & 633 & 7.6 \\
HIC36 & 927 & 981 & 5.8 \\
Hip acceleration $/\left(\mathrm{m} \cdot \mathrm{s}^{-2}\right)$ & 841 & 866 & 3.0 \\
Chest3MS/(m·s & 646 & 631 & 2.3 \\
FFCL/(N) & 1688 & 1712 & 1.4 \\
FFCR/(N) & 1452 & 1627 & 12 \\
\hline
\end{tabular}

From table 1 we can see the key index of this model the calculation error is within $15 \%$.It is proved that the model accurately reflects the whole process of collision. The model is correct and effective.

\section{Headrest parameters design}

Rear passenger is very easy to hit the front seat headrest in frontal impact .Analysis the influence of head parameters on injury to rear seat occupants to reduce the rear passenger's head, chest injury by the best headrest parameters. From Table 2 to Table4 are different headrest parameters on injury to rear passenger.

Table 2: Headrest horizontal distance on injury to rear passenger

\begin{tabular}{lccccc}
\hline \multirow{2}{*}{ Damage index } & \multicolumn{5}{c}{ Headrest horizontal distance /(m) } \\
\cline { 2 - 6 } HIC & 0.18 & 0.20 & 0.22 & 0.24 & 0.26 \\
T3MS/(m·s' $)$ & 881 & 921 & 862 & 903 & 928 \\
$\mathrm{FFCL} /(\mathrm{N})$ & 785 & 792 & 785 & 785 & 785 \\
$\mathrm{FFCR} /(\mathrm{N})$ & 1687 & 1689 & 1688 & 1684 & 1679 \\
\hline
\end{tabular}

Table 3: Headrest height on injury to rear passenger

\begin{tabular}{|c|c|c|c|c|c|}
\hline \multirow{2}{*}{ Damage index } & \multicolumn{5}{|c|}{ Headrest height $/(\mathrm{m})$} \\
\hline & 0.55 & 0.57 & 0.59 & 0.61 & 0.63 \\
\hline $\mathrm{HIC}$ & 851 & 838 & 831 & 839 & 840 \\
\hline $\mathrm{T} 3 \mathrm{MS} /\left(\left(\mathrm{m} \cdot \mathrm{s}^{-2}\right)\right.$ & 786 & 786 & 786 & 787 & 787 \\
\hline FFCL/(N) & 1682 & 1685 & 1685 & 1682 & 1680 \\
\hline $\mathrm{FFCR} /(\mathrm{N})$ & 1476 & 1473 & 1472 & 1475 & 1475 \\
\hline \multirow{2}{*}{ Damage index } & \multicolumn{5}{|c|}{ Headrest stiffness $/ \%$} \\
\hline & 0.6 & 0.8 & 1 & 1.2 & 1.4 \\
\hline $\mathrm{HIC}$ & 838 & 842 & 846 & 850 & 853 \\
\hline $\left.\mathrm{T} 3 \mathrm{MS} /\left(\mathrm{m} \cdot \mathrm{s}^{-2}\right)\right)$ & 786 & 786 & 786 & 786 & 786 \\
\hline FFCL/(N) & 1682 & 1685 & 1685 & 1682 & 1680 \\
\hline $\mathrm{FFCR} /(\mathrm{N})$ & 1473 & 1473 & 1475 & 1472 & 1473 \\
\hline
\end{tabular}

Table 2 to Table 4 show that with the increase of headrest horizontal distance and headrest height, rear passenger head injury decreased and then increased again, but chest and femur injury 
are almost unchanging; with the increase of headrest stiffness, only rear passenger head injury increase, chest and femur injury remain stable.

\section{Backrest parameters design}

Make the headrest parameters unchanged, and change the values of backrest angle, backrest stiffness, and backrest horizontal distance. Analysis the different values of damage to other parts of the rear-seat passenger.From Table5 to Table7 are different backrest parameters on injury to rear passenger.

Table5 to Table7 shows that with the increase of backrest stiffness, rear passenger head and chest injury increase, and femur injury remain stable; with the increase of Backrest angle, rear passenger chest and femur injury increase, but head injury decrease and then increase; with the increase of backrest horizontal distance, rear passenger chest and femur injury increase, but head injury increase and then decrease.

Table 5: Backrest angle on injury to rear passenger

\begin{tabular}{lccccc}
\hline \multirow{2}{*}{ Damage index } & \multicolumn{5}{c}{ Backrest angle/ $\left({ }^{\circ}\right)$} \\
\cline { 2 - 6 } & 19 & 21 & 23 & 25 & 27 \\
\hline HIC & 831 & 824 & 833 & 838 & 928 \\
T3MS/(m-s $\left.{ }^{-2}\right)$ & 749 & 764 & 772 & 782 & 788 \\
FFCL/(N) & 1698 & 1701 & 2406 & 2412 & 2534 \\
FFCR/(N) & 2571 & 2572 & 2572 & 2575 & 2575 \\
\hline
\end{tabular}

Table 6: Backrest stiffness on injury to rear passenger

\begin{tabular}{lccccc}
\hline \multirow{2}{*}{ Damage index } & \multicolumn{5}{c}{ backrest stiffness/\% } \\
\cline { 2 - 6 } & 0.6 & 0.8 & 1 & 1.2 & 1.4 \\
\hline HIC & 807 & 809 & 838 & 861 & 882 \\
T3MS/(m·s-2) & 773 & 784 & 785 & 781 & 782 \\
FFCL/(N) & 2358 & 2357 & 2358 & 2358 & 2358 \\
FFCR/(N) & 2566 & 2567 & 2567 & 2566 & 2567 \\
\hline
\end{tabular}

Table7: Backrest horizontal distance on injury to rear passenger

\begin{tabular}{lccccc}
\hline \multirow{2}{*}{ Damage index } & \multicolumn{5}{c}{ backrest horizontal distance/(m) } \\
\cline { 2 - 6 } & 0.41 & 0.43 & 0.45 & 0.47 & 0.49 \\
\hline HIC & 817 & 903 & 862 & 903 & 928 \\
T3MS/(m·s-2) & 785 & 792 & 785 & 785 & 785 \\
FFCL/(N) & 1698 & 1698 & 1740 & 2115 & 2869 \\
FFCR/(N) & 2566 & 2567 & 2567 & 2566 & 2567 \\
\hline
\end{tabular}

\section{Conclusions}

This article we use MADYMO software to establish the rear seat passenger constraint system model .With this model, we research the influence of headrest and backrest parameters on injury to rear passenger HIC, 3MS, and femur force. Here we may draw the following conclusions.

(1) This model can effectively simulate the restraint system response in the collision process and fully show the occupant injury indicators. It is easy to evaluate the security of the restraint system.

(2) It is observed that headrest horizontal distance and height should be set properly to reduce the rear passenger HIC, and headrest stiffness should decrease within the permissible range.

(3) Appropriate backrest angle can effectively decrease the passenger HIC. Decrease the backrest angle can reduce the passenger Chest 3MS and femur force. Backrest stiffness and backrest horizontal distance should be reduced within the permissible range. 


\section{References}

[1] Munemasa S. \& Minoru Y. 2005. Method to evaluate the effect of safety belt use by rear seat passengers on the injury severity of front seat occupants. Accident Analysis and Prevention 10(37): 5-17.

[2] Ralf R. \& Rainer H. 2004. Application of stochastic simulation in the automotive industry. $S A E$ PaPer 5(28): 54-57.

[3] Astrid W. 2006. Applieation of uncertainty management to MADYMO occupant dynamics simulation. SAE Paper 27(3): 78-81.

[4] Joseph T. \& Lauire S. 2006. Optimization of driver-side airbag and restraint system by occupant dynamics simulation. SAE Paper 27(3): 56-61

[5] Jo H, Eun K Y. 2007. A study on the influence of the seat back strength on neck injury in low speed rear offset impacts[J]. Journal of the Korean Society of Mechanical Technology 09(4): 16.

[6] Jo H. \& Eun K.Y. 2009. A study on the influence of the seat and head restraint foam stiffnesses on neck injury in low speed offset rear impacts. International Journal of Precision Engineering and Manufacturing 10(2): 105-110.

[7] Beheshti H.K \& Lankarani H. An investigation in crashworthiness evaluation of aircraft seat cushions at extreme ranges of temperature. 2010. Journal of Mechanical Science and Technology 24(5): 1105-1110. 